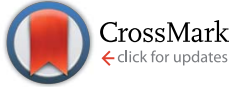

Cite this: RSC Adv., 2017, 7, 7338

Received 19th November 2016 Accepted 9th January 2017

DOI: 10.1039/c6ra27028j

www.rsc.org/advances

\section{Combined thermal and FTIR analysis of porous silicon based nano-energetic films $\uparrow$}

\begin{abstract}
A. Plummer, ${ }^{a}$ V. A. Kuznetsov, ${ }^{\text {ab }}$ J. R. Gascooke, ${ }^{a}$ J. Shapter $^{\text {ac }}$ and N. H. Voelcker ${ }^{\star d}$
Nanoporous silicon (pSi) films on a silicon wafer were loaded with sodium perchlorate (SP) and perfluoropolyether (PFPE) oxidising agents to generate a pyrotechnic energetic material. The potentially violent reaction between the silicon and the loaded oxidising agent was studied using correlated differential scanning calorimetry (DSC) and FTIR spectroscopy for samples heated continuously between ambient and $500{ }^{\circ} \mathrm{C}$. We observed that the energetic reaction between pSi and SP depended on the presence of various hydride species on the surface of freshly etched $\mathrm{pSi}$, and on formation of volatile free radical species released during either oxidation of the surface in the presence of air at about $200{ }^{\circ} \mathrm{C}$ or during desorption of the hydride above $270{ }^{\circ} \mathrm{C}$ in the absence of oxygen. However, energetic reactions between pSi and PFPE were delayed until pyrolysis of the PFPE above $390{ }^{\circ} \mathrm{C}$ in the absence of oxygen, suggesting PFPE's suitability for pyrotechnics applications. Correlated thermal and spectroscopic methods of analysis gave new insights into the earliest stages of the reaction of these energetic materials.
\end{abstract}

\section{Introduction}

Porous silicon ( $\mathrm{pSi}$ ) is a nanostructured material prepared by the electrochemical etching of silicon wafers using various hydrofluoric acid (HF) based etching solutions resulting in nano- to micro-metre sized cavities in the surface whilst leaving the bulk dimensions of the wafer unchanged. ${ }^{1}$ Manipulation of the etching conditions permits precise control over the resulting porous layer, including the size of the pores, the shape (from highly ordered channels to highly disordered sponge-like structures), depth and overall porosity. ${ }^{1}$ The explosive behaviour of pSi films impregnated by an oxidising agent has been recognised and steadily investigated since $1992 .^{2}$ The behaviour originates from the very high internal surface area of pSi (up to $800 \mathrm{~m}^{2} \mathrm{~g}^{-1}$ ) permitting a very intimate mixture between the oxidising agent and the fuel (silicon), leading to materials that are relatively stable at room temperature and are able to react explosively upon application of an energy stimulus. Indeed, $\mathrm{pSi}$ energetic materials (pSi EM's) prepared in this way are sensitive to a wide variety of stimuli. Methods of initiation that have been reported include heating using, for example, a hot-plate ${ }^{3}$ or

\footnotetext{
${ }^{a}$ Centre of Expertise in Energetic Materials, School of Chemical and Physical Sciences, Flinders University, 5042, Bedford Park, Australia

${ }^{b}$ Weapons and Combat Systems Division, Defence Science and Technology Group, Edinburgh, SA 5111, Australia

${ }^{c}$ Centre for Nanoscale Science and Technology, School of Chemical and Physical Sciences, Flinders University, 5042, Bedford Park, Australia

${ }^{d}$ Future Industries Institute, University of South Australia, 5095, Mawson Lakes, Australia. E-mail: nico.voelcker@unisa.edu.au; Tel: +61 883025508

$\dagger$ Electronic supplementary information (ESI) available. See DOI: 10.1039/c6ra27028j
}

a hot bridge-wire, ${ }^{4,5}$ mechanical stimulus (such as scratching the surface or friction), ${ }^{6}$ or an electrical spark. ${ }^{6,7}$ Additionally, laser ignition of pSi energetic materials has been reported using a variety of wavelengths and laser fluences. ${ }^{6,8-10}$

A variety of oxidising agents (typically nitrate or perchlorate salts) have been shown to react energetically with pSi. Sodium perchlorate (SP) has emerged as the oxidiser of choice since it delivers the most powerful and consistent energetic reaction. ${ }^{2}$ Conveniently, controlling the material properties of the $\mathrm{pSi}$ substrate (by tuning the etching conditions) permits control over the stoichiometry of the system by limiting the volume of the pores available to be filled. The burning rate of pSi energetic films has been reported from as high as $3600 \mathrm{~m} \mathrm{~s}^{-1}$ (ref. 11) to less than $1 \mathrm{~m} \mathrm{~s}^{-1}$. $^{12}$ The choice of oxidising agent, porosity, pore depth and pore diameter are all interdependent factors which govern the burning rate of the system. Fluorinated polymers (such as perfluoropolyether (PFPE)) have recently been investigated as an alternative to ionic oxidising agents, with reported burning rates typically less than $1 \mathrm{~m} \mathrm{~s}^{-1}$. $^{12}$

It is recognised that pSi EM's can be excessively sensitive, rendering those materials ill-suited for real world applications such as MEMS actuators or air-bag initiators envisaged in earlier works., ${ }^{2,10,13}$ Knowledge of the reaction mechanism between pSi and an oxidising agent is an important factor to help understand the excessive sensitivity, and may assist in the selection of oxidising agent or material treatment regimes in order for these materials to be translated into real-world applications.

Simple bomb calorimetry can determine the total energy released during reaction of a material. ${ }^{14}$ However, the reaction of an energetic material involves sometimes complex decomposition 
stages and formation of intermediate species. Investigation of these processes by controlled thermal analysis methods can yield important information, including reaction endo- and exotherms, or intermediate transition or decomposition temperatures all of which gives an insight to the mechanism of the reaction. ${ }^{15}$

Investigating the reaction between the pSi surface with liquid oxygen, Kovalev et al. ${ }^{\mathbf{1 6}}$ first proposed that hydride termination of the freshly etched pSi surface was an essential passivating barrier to prevent spontaneous oxidation. Rupturing the $\mathrm{Si}-\mathrm{H}$ surface bonds or sub-surface $\mathrm{Si}-\mathrm{Si}$ bonds by various means created free radicals susceptible to reaction with oxygen. The exothermic reaction between a single Si atom and oxygen molecule releases sufficient energy to disrupt neighbouring bonds. A single point of initiation can then rapidly cascade up to an explosive reaction.

Churaman et al. ${ }^{17}$ investigated the mechanism of the reaction between a pSi film (approx. $4 \mathrm{~nm}$ pore diameter, $40 \mu \mathrm{m}$ layer thickness) and SP. Using differential scanning calorimetry (DSC) dehydration endotherms of the monohydrated SP within the pSi pores were observed at approximately $51{ }^{\circ} \mathrm{C}$ and $149^{\circ} \mathrm{C}$, a phase transition of the SP at $307^{\circ} \mathrm{C}$, and finally an explosive reaction at $320{ }^{\circ} \mathrm{C}$. No significant exotherms were observed below the temperature of explosion. They concluded that the mixture commenced reaction initially by formation of reactive ions through dissociation of the SP or $\mathrm{H}_{2} \mathrm{O}$ during these dehydration steps, which are then free to react with the pSi surface. Again it was observed that the presence of the hydride termination on the pSi surface was essential to promote a strong explosive reaction.

Becker et al. ${ }^{18}$ investigated the influence of atmospheric conditions on the reactivity of pSi films impregnated with SP. Using bomb calorimetry, freshly etched pSi prepared by galvanic corrosion (up to $150 \mu \mathrm{m}$ thick layers, 62 to $69 \%$ porosity, pore sizes 2.7 to $3.1 \mathrm{~nm}$ ) loaded with SP yielded gross reaction enthalpies of $9.9 \mathrm{~kJ} \mathrm{~g}^{-1}$ of $\mathrm{pSi}$ in a $\mathrm{N}_{2}$ atmosphere and $27.3 \mathrm{~kJ} \mathrm{~g}^{-1}$ in $\mathrm{O}_{2}$. They further observed that oxygen back bonding beneath the hydride-terminated pSi surface resulted in a weak exotherm at about $250{ }^{\circ} \mathrm{C}$. This was confirmed by FTIR spectroscopy. In the absence of the hydride termination, no energetic reaction was observed. Hence, the presence of the hydride termination on the pSi surface was essential to enabling the material to react explosively according to the authors. They further concluded that the substantial difference in the total energy of the reaction recorded between $\mathrm{N}_{2}$ and $\mathrm{O}_{2}$ atmospheres was due to the mixture being substantially fuel rich (a limitation imposed by the available pore volume within the pSi layer), thereby allowing remaining Si to react with the oxygen after the main reaction with the $S P$.

Parimi et $a l .{ }^{19}$ studied the reactivity of various pSi EM's using DSC and TGA, investigating the influence of doping type and doping concentration of the original Si wafer. Wafer dopant concentration and type influenced the reactivity of the material, not directly by contributing to the reaction between the pSi and the oxidising agent, but indirectly by impacting on the morphology and specific surface area of the pSi generated by means of anodisation. Studying the propagation of the flame through pSi EMs of different morphology, ${ }^{20}$ the authors observed that the peak temperature of the first and strongest exotherm (which was attributed to the solid phase reaction between pSi and SP) shifted to lower temperatures as the specific surface area of the pSi increased, from approximately $400{ }^{\circ} \mathrm{C}$ at a surface area of $284 \mathrm{~m}^{2} \mathrm{~g}^{-1}$ to approx. $280{ }^{\circ} \mathrm{C}$ at a surface area of $730 \mathrm{~m}^{2} \mathrm{~g}^{-1}$. A calculation of the activation energies for these two materials gave values of $124.5 \mathrm{~kJ} \mathrm{~mol}^{-1}$ for the low surface area pSi and $72.1 \mathrm{~kJ} \mathrm{~mol}^{-1}$ for the high surface area pSi. From those calculations and others, it was determined that the propagation of the flame through pSi was due to a combination of both conductive and convective burning, not simply a conductive mechanism as observed in other solid-phase energetic materials.

Infrared spectroscopy is a versatile technique often applied to $\mathrm{pSi}$ research due to the wealth of information available about the chemical structure of this high surface area material. Oxidation of a pSi surface heated continuously in an $\mathrm{O}_{2}$ atmosphere was observed by Mawhinney et al. ${ }^{21}$ with the results showing that the reaction proceeded initially by insertion of oxygen into the $\mathrm{Si}-\mathrm{Si}$ bonds behind the $\mathrm{Si}-\mathrm{H}$ surface species when the temperature exceeded $300{ }^{\circ} \mathrm{C}$. As the oxidation proceeded, the hydride species were gradually replaced by hydroxyl groups and eventually, the surface was completely oxidised. Likewise, Salonen et al. ${ }^{22}$ used FTIR in combination with DSC, showing a strong exothermic reaction of pSi heated in air commencing at about $200{ }^{\circ} \mathrm{C}$, peaking at approximately $300{ }^{\circ} \mathrm{C}$ and attributed this to back bond oxidation of the pSi surface. Furthermore, a broad exothermic tail observed in the DSC rising from about $400{ }^{\circ} \mathrm{C}$ and terminating at approx. $650{ }^{\circ} \mathrm{C}$ was attributed to the formation of surface hydroxyl groups. However, in their study Salonen et al. ${ }^{22}$ cooled the samples after heating, prior to FTIR analysis.

Both DSC and FTIR studies independently yield valuable information about the structure of $\mathrm{pSi}$ and the possible reaction pathways. Significantly, Mawhinney et al. ${ }^{21}$ recognised the need to continuously record spectra during the heating process to minimise kinetic effects caused by cooling of a heated sample prior to measurement. Such problems would be exacerbated for the fast reacting pSi EM's studied here. It is therefore the aim of this work to combine these two techniques to obtain valuable real-time spectroscopic information regarding the reaction of $\mathrm{pSi}$, and to correlate that to observed reactions in the thermal analysis.

\section{Materials and methods}

\section{Porous silicon preparation}

Porous silicon was prepared from p-type boron doped wafers, 3$6 \Omega \mathrm{cm}$ resistivity, $\langle 100\rangle$ orientation, supplied by Virginia Semiconductors. Hydrofluoric acid (48\% aqueous solution, Merck Chemicals) was diluted with acetonitrile to a final volumetric concentration of $20 \%$. Electrochemical etching was conducted using standard techniques ${ }^{\mathbf{1 , 3}}$ in a Teflon etching cell incorporating a platinum cathode and stainless steel anode. ${ }^{23}$ The etching cell used in these experiments produced an etched area $45 \mathrm{~mm}$ long by $8 \mathrm{~mm}$ wide (etch area of $3.79 \mathrm{~cm}^{2}$ ). Electrochemical etching was performed by a TTi PLH-250 power 
supply, operated under conditions of constant current controlled by a purpose-built LabVIEW interface on a Windows PC. The applied current was pulsed with a $66 \%$ duty cycle $(10 \mathrm{~s}$ on, $5 \mathrm{~s}$ off), for a desired number of cycles, at a current density of $45 \mathrm{~mA} \mathrm{~cm}^{-2}$ for an applied current time of 30 minutes (45 min's total etch time). Previous work has determined that these etching conditions produce pSi surfaces with pore sizes of $3.6 \pm$ $1.4 \mathrm{~nm}$, a porosity of $64.7 \pm 0.5 \%$ and a depth of $42.9 \pm 0.4 \mu \mathrm{m} .{ }^{23}$ Wafers were washed with ethanol and acetone prior to and after etching, and dried in a stream of $\mathrm{N}_{2}$ gas. All samples were stored in a desiccator when not being handled. For all investigations reported here, the pSi layer remained attached to the supporting Si wafer. In this configuration, only the pSi forms the reactive material and the supporting wafer takes no part in the reaction. ${ }^{24}$ These wafers were cut into suitably sized smaller samples (approximately $4 \times 4 \mathrm{~mm}^{2}$ for DSC experiments and approximately $4 \times 8 \mathrm{~mm}^{2}$ for FTIR experiments) prior to loading with the oxidising agent.

\section{Loading of oxidant into pSi}

A stock solution of SP monohydrate (Ajax Chemicals) was prepared at a concentration of $400 \mathrm{~g} \mathrm{~L}^{-1}$ in methanol. The solution of the selected oxidising agent was micropipetted onto the wafer and impregnated into the pores as the solvent evaporated in a stream of $\mathrm{N}_{2}$ gas, leaving the oxidising agent deposited into the pores, an effect substantially exacerbated for wafers that were sectioned for DSC/FTIR analysis. As had been noted elsewhere, ${ }^{\mathbf{1 3}, 18}$ crystals of SP would tend to nucleate on the surface instead of within the pores as the solvent evaporated. This effect could be reduced by careful evaporation using a gentle stream of $\mathrm{N}_{2}$, and small residual surface crystals not contributing to the energetic reaction were gently removed prior to analysis.

Secondly, a stock solution of the PFPE (Fomblin Y HVAC 25/ 9) was prepared at a concentration of $200 \mathrm{~g} \mathrm{~L}^{-1}$ in the fluorinated solvent perfluoro(butyltetrahydrofuran) (Fluorinert FC75). Fomblin $\mathrm{Y}$ is a high viscosity liquid at room temperature. Impregnation of this material into the pores required the stock solution to be pipetted onto the surface, followed by evaporation under vacuum in a desiccator with subsequent back-filling of the vessel using $\mathrm{N}_{2}$ - three successive steps were required in order to load the wafer.

The mass of the EM (i.e. the net explosive quantity) was determined gravimetrically. Samples were weighed prior and subsequent to loading with the oxidising agent, and the unreactive supporting wafer was weighed subsequent to analysis once the pSi layer had been stripped away using dilute aqueous potassium hydroxide.

\section{Thermal analysis}

DSC experiments were conducted on a TA Instruments 8020 DSC at a heating rate of $20{ }^{\circ} \mathrm{C} \mathrm{min}^{-1}$, in open aluminium pans with a chamber purge gas of either dry air (BOC Instrument grade compressed air, $<25 \mathrm{ppm}_{2} \mathrm{O}^{25}$ ) or $\mathrm{N}_{2}$ at a rate of $50 \mathrm{~mL}$ $\min ^{-1}$, between ambient and $600{ }^{\circ} \mathrm{C}$.

\section{Spectroscopic analysis}

FTIR experiments were conducted separately to the DSC, conducted on samples prepared and loaded under the same conditions, and under the same heating and atmospheric regime. The instrument used was a Nicolet Nexus 870 FTIR using a liquid $\mathrm{N}_{2}$ cooled MCT detector and 16 scans per measurement point. Samples were heated by conduction on a Linkam FTIR600 hot stage accessory, heated at rate of $20{ }^{\circ} \mathrm{C}$ $\min ^{-1}$, with transmission spectra collected between 30 and $510{ }^{\circ} \mathrm{C}$ at intervals of approximately $20{ }^{\circ} \mathrm{C}$. This was also run with controlled atmospheres of either $\mathrm{N}_{2}$ or dried air (supplied through a Parker Bailish purge gas generator), and used zinc selenide IR transparent windows. Spectra were all recorded in transmission mode at pre-determined temperatures as the sample was being continuously heated. The temperature of the sample increased by approximately $2{ }^{\circ} \mathrm{C}$ during the time taken to actually record the spectra. Whilst it is recognised that this temperature change introduced a small uncertainty, it was felt that this was an acceptably necessary experimental compromise.

All spectra collected for an individual sample were background corrected to compensate for the decreasing transparency of $\mathrm{Si}$ at the temperatures of these experiments - details of the correction method are provided in the ESI. $\uparrow$ Table 1 lists the characteristic spectral peaks for various species involved in this investigation.

\section{Results and discussion}

DSC scans obtained for the various samples used in this study are shown in Fig. 1. Each scan has been offset to allow comparison between the different samples. For the same samples, 2D images showing FTIR spectra as a function of temperature are compiled in Fig. 2. Fig. 3 depicts FTIR spectra (extracted from data forming Fig. 2) recorded at $150{ }^{\circ} \mathrm{C}$ to allow comparison of each of the material combinations and to highlight the relevant peaks. Each of the eight sample conditions are compared in further detail and presented in the ESI, Fig. S2a to h. $\dagger$

\section{Thermal behaviour of blank pSi}

Unloaded pSi displayed significant evidence of oxidation when heated in air (Fig. 1a and 2a). By means of DSC, we observed an onset temperature of the exothermic oxidation reaction at approximately $200{ }^{\circ} \mathrm{C}$ peaking at $292{ }^{\circ} \mathrm{C}$. Comparing this to the FTIR spectral data, the main transition between a fresh and oxidised surface was initially visible at between 230 and $250{ }^{\circ} \mathrm{C}$ and appeared substantially complete by approximately $350{ }^{\circ} \mathrm{C}$. This is most clearly indicated by the decrease in intensity of the surface hydride triplet peaks (centred at $2109 \mathrm{~cm}^{-1}$ ) with an associated increase in the back-bonded oxygen $\left(\mathrm{OSi}-\mathrm{H}_{x}\right)$ represented by the peaks at $\approx 2254 \mathrm{~cm}^{-1}$, and is supported by a very strong absorbing band between $\approx 800-1200 \mathrm{~cm}^{-1}$ (amorphous $\mathrm{Si}-\mathrm{O}_{2}$ absorbance) and a weak peak at $3730 \mathrm{~cm}^{-1}(\mathrm{SiO}-\mathrm{H}$ stretch). These observations agree reasonably well with those of Salonen et al. ${ }^{22}$ 
Table 1 Characteristic frequencies of relevant transitions of species encountered during this study

\begin{tabular}{|c|c|c|}
\hline Wavenumber $\left(\mathrm{cm}^{-1}\right)$ & Transition & Ref. \\
\hline $616,621,643$ & $\mathrm{ClO}_{4}^{-}$vibration & 26 \\
\hline $615,622,666$ & $\begin{array}{l}\mathrm{Si}-\mathrm{H}_{x} \text { deformation, overlapped } \\
\text { with } \mathrm{Si} \text { crystal modes }\end{array}$ & 21 \\
\hline $671,730,776$ & $\mathrm{C}-\mathrm{C} / \mathrm{C}-\mathrm{O} / \mathrm{C}-\mathrm{F} / \mathrm{C}-\mathrm{F}_{2} / \mathrm{C}-\mathrm{F}_{3}$ stretch & 27 \\
\hline 840 & $\mathrm{Si}-\mathrm{N}$ asymmetric stretch $\left(>800^{\circ} \mathrm{C}\right)$ & 28 \\
\hline 841,877 & $\mathrm{O}-\mathrm{SiH}_{x}$ (unknown mode) & 21 \\
\hline 906 & $\mathrm{ClO}_{4}^{-}$vibration & 26 \\
\hline 915 & $\mathrm{Si}-\mathrm{H}_{2}$ scissoring & 21 \\
\hline 940 & $\mathrm{Si}-\mathrm{F}$ stretch & 29 \\
\hline 950-1250 (broad) & Amorphous $\mathrm{Si}-\mathrm{O}_{2}$ absorbance & 21 \\
\hline 980 & Overlapping $\mathrm{C}-\mathrm{C} / \mathrm{C}-\mathrm{F}_{2} / \mathrm{C}-\mathrm{F}_{3}$ stretch & 27 \\
\hline $1011,1127,1192$ & $\mathrm{ClO}_{4}^{-}$vibration & 26 \\
\hline 1015,1121 & $\mathrm{Si}-\mathrm{O}-\mathrm{Si}$ vibration & 21 \\
\hline $1029,1190,1826$ & $\mathrm{Si}-\mathrm{F}_{4}$ (unknown mode) & 30 \\
\hline 1108 & $\mathrm{Si}-\mathrm{O}-\mathrm{Si}$ crystal stretch & 21 \\
\hline 1110 & $\mathrm{ClO}_{4}^{-}$vibration & 26 \\
\hline \multirow[t]{2}{*}{ 1131-1345 } & Multiple overlapping & 27 \\
\hline & $\mathrm{C}-\mathrm{C} / \mathrm{CF}_{2} / \mathrm{CF}_{3}$ stretch & \\
\hline 1157 & $\mathrm{C}-\mathrm{F}_{3}$ (unknown mode) & 30 \\
\hline 1200 & $\mathrm{C}-\mathrm{F}$ stretch & 31 \\
\hline $1283,1539,2186,2561$ & $\mathrm{C}-\mathrm{F}_{4}$ (unknown mode) & 30 \\
\hline $1300-1150$ & $\mathrm{C}-\mathrm{O}-\mathrm{C} ; \mathrm{C}-\mathrm{F}$ stretch & 31 \\
\hline 1372 & Overlapping $\mathrm{C}-\mathrm{C} / \mathrm{CF}_{2} / \mathrm{CF}_{3}$ stretch & 27 \\
\hline 1929 & $\mathrm{COF}_{2}$ (unknown mode) & 30 \\
\hline $2090,2115,2141$ & $\mathrm{Si}-\mathrm{H}_{x}$ stretch & 21 \\
\hline 2214,2273 & OSi- $\mathrm{H}_{x}$ stretch & 21 \\
\hline 3736 & $\mathrm{SiO}-\mathrm{H}$ stretch & 21 \\
\hline 3745 & $\mathrm{SiO}-\mathrm{H}$ stretch & 21 \\
\hline $3750-4250$ & H-F stretch & 30 \\
\hline
\end{tabular}

However, for pSi heated in $\mathrm{N}_{2}$ (Fig. $1 \mathrm{~b}$ and $2 \mathrm{~b}$ ), the DSC showed a weak exothermic peak with an onset from approximately $270{ }^{\circ} \mathrm{C}$ and peaking at approximately $380{ }^{\circ} \mathrm{C}$. FTIR

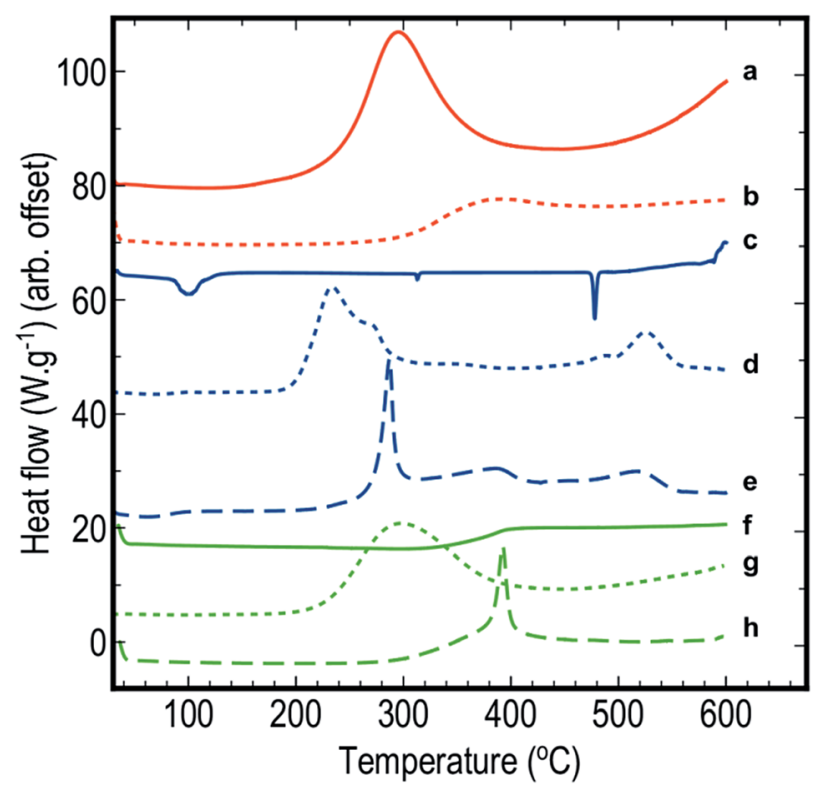

Fig. 1 DSC scans of (a) blank pSi in air, (b) blank pSi in $N_{2}$, (c) blank SP in air, (d) pSi/SP EM in air, (e) pSi/SP EM in $\mathrm{N}_{2}$, (f) blank PFPE in air, (g) pSi/ PFPE EM in air, and (h) pSi/PFPE in $\mathrm{N}_{2}$. spectra displayed the typical triplet of peaks at $2109 \mathrm{~cm}^{-1}$ associated with multiple $\mathrm{Si}-\mathrm{H}_{x}$ stretching reducing gradually to a single peak centred at $2082 \mathrm{~cm}^{-1}$ between $350-400{ }^{\circ} \mathrm{C}$. The onset temperature of this transition observed on the FTIR spectra $\left(\approx 350{ }^{\circ} \mathrm{C}\right)$ was higher than observed on the DSC $(\approx 270$ ${ }^{\circ} \mathrm{C}$ ), however the FTIR resolution may prevent subtle changes from being observed at lower temperatures. Similarly, the peak at $910 \mathrm{~cm}^{-1}\left(\mathrm{Si}-\mathrm{H}_{2}\right.$ scissoring) decreased over the temperature range tested, disappearing completely by $\approx 400{ }^{\circ} \mathrm{C}$. It seems that pSi heated in $\mathrm{N}_{2}$ simply desorbs the surface hydrogen slowly commencing at $\approx 270{ }^{\circ} \mathrm{C}$. By the end of the experimental run at $503{ }^{\circ} \mathrm{C}$ the hydride peaks still had not completely disappeared, and the absence of gaseous oxygen prevents further oxidation of the surface. A very weak peak at $850 \mathrm{~cm}^{-1}$ appears at $389^{\circ} \mathrm{C}$ and increases intensity with temperatures up to $468{ }^{\circ} \mathrm{C}$. This peak may be attributed to incorporation of nitride species on the $\mathrm{Si}$ surface based on the study by Scardera et al. ${ }^{28}$ However, their study was conducted on samples of thin silicon nitride films deposited at $400{ }^{\circ} \mathrm{C}$ and annealed to over $800{ }^{\circ} \mathrm{C}$, and revealed multiple fine peaks centred around $840 \mathrm{~cm}^{-1}$ that were assigned to modes of $\mathrm{Si}-\mathrm{N}_{x}$ asymmetric stretching depending on the annealing temperature. Thus, we tentatively assign our observed peak at $850 \mathrm{~cm}^{-1}$ to surface nitride species.

\section{Decomposition and reaction of $\mathrm{pSi} / \mathrm{SP}$ energetic materials}

The FTIR spectra for SP as a function of temperature in air (Fig. 2c) showed initial strong absorption bands between 10501200, 1600-1700 and 3100-3700 $\mathrm{cm}^{-1}$ which disappeared at temperatures between 110 and $130{ }^{\circ} \mathrm{C}$. A first moderate endothermic peak was seen in the DSC scans (Fig. 1c) at approximately $100{ }^{\circ} \mathrm{C}$. This peak was attributed to dehydration of the $\mathrm{NaClO}_{4} \cdot \mathrm{H}_{2} \mathrm{O}$, and the FTIR spectra appeared to reflect this change. Peaks at 619 and $1108 \mathrm{~cm}^{-1}$ associated with various vibrations of the perchlorate ion were persistently observed. A weak peak at $2046 \mathrm{~cm}^{-1}$ was stable across the temperature range is also associated with SP. In the DSC scan, a second weak endothermic peak at $313{ }^{\circ} \mathrm{C}$ was attributed to a phase change of the SP - this was not observed in the FTIR spectra. Sample melting occurred at $477^{\circ} \mathrm{C}$ according to the DSC and FTIR. The combined thermal and spectroscopic data presented here agree well with previous work, ${ }^{26,32}$ even though both studies used the two analytical techniques in isolation.

When SP was incorporated into the pSi layer to create an EM, significant changes in the FTIR spectra were observed compared to blank pSi and pure SP (Fig. 2a and c). Initially, the strong absorption band centred at $1108 \mathrm{~cm}^{-1}$ due to SP was clearly distinguishable from relevant pSi peaks at $910 \mathrm{~cm}^{-1}$ and the triplet band at $\approx 2109 \mathrm{~cm}^{-1}$ for samples heated in either air or $\mathrm{N}_{2}$ atmosphere (Fig. 2d, e and 3c).

For pSi/SP heated in air (Fig. 1d and 2d), the FTIR spectra displayed a clear transition commencing at approximately $200{ }^{\circ} \mathrm{C}$ - this correlates with the onset temperature recorded in the DSC $\left(203{ }^{\circ} \mathrm{C}\right)$. This change was rapid and complete by approximately $250{ }^{\circ} \mathrm{C}$ (with DSC recording a maximum at 233 ${ }^{\circ} \mathrm{C}$ ). These changes are associated with strong oxidation of the $\mathrm{pSi}$ surface as evident from the disappearance of the $\mathrm{Si}-\mathrm{H}_{x}$ 


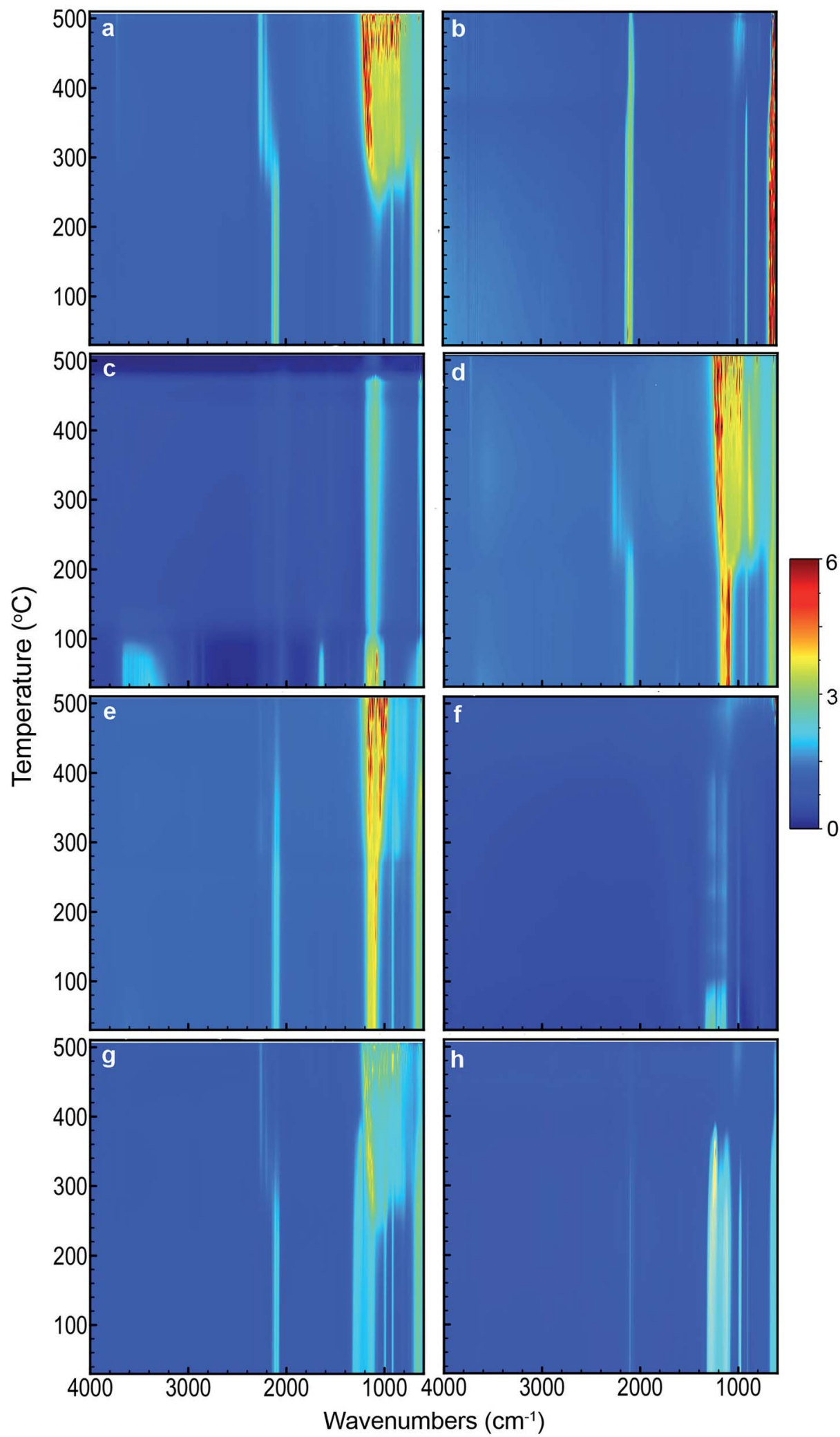

Fig. 2 2D FTIR spectra as a function of temperature of (a) blank pSi in air, (b) blank pSi in $\mathrm{N}_{2}$, (c) blank SP in air, (d) pSi/SP EM in air, (e) pSi/SP EM in $\mathrm{N}_{2}$, (f) blank PFPE in air, (g) pSi/PFPE EM in air, and (h) pSi/PFPE in $\mathrm{N}_{2}$.

triplet band and associated appearance of the OSi- $\mathrm{H}_{x}$ back bonding (approximately at $2254 \mathrm{~cm}^{-1}$ ). The broad absorption band between $\approx 800-1200 \mathrm{~cm}^{-1}$ was also attributed to $\mathrm{Si}-\mathrm{O}_{x}$ vibrations. Changes in the perchlorate absorption peaks at $\approx 1100 \mathrm{~cm}^{-1}$ were masked at temperatures above $200{ }^{\circ} \mathrm{C}$ due to broad $\mathrm{Si}-\mathrm{O}_{x}$ absorption $\left(800-1200 \mathrm{~cm}^{-1}\right)$. These changes 


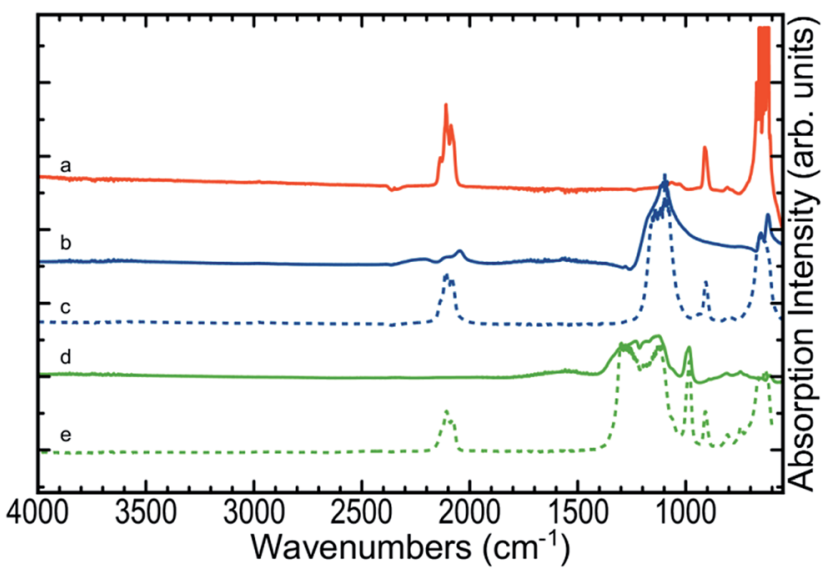

Fig. 3 FTIR spectra of (a) blank pSi, (b) blank SP, (c) pSi/SP EM, (d) blank PFPE, and (e) pSi/PFPE EM, collected at $150{ }^{\circ} \mathrm{C}$ for samples heated in a $\mathrm{N}_{2}$ atmosphere. The triplet of peaks at $\approx 2109 \mathrm{~cm}^{-1}$ (Si- $\mathrm{H}_{x}$ vibration) and a single peak at $\approx 910 \mathrm{~cm}^{-1}\left(\mathrm{Si}-\mathrm{H}_{2}\right.$ scissoring) are specific for the pSi surface and clearly distinguished from a strong absorption band between $\approx 1000$ and $1200 \mathrm{~cm}^{-1}$ (associated to multiple perchlorate vibration modes) and a sharp absorption peak at $\approx 980 \mathrm{~cm}^{-1}$ attributed to overlapping PFPE $\mathrm{CF}_{2} / \mathrm{CF}_{3}$ vibrations.

occurred at a temperature far lower than the melting point of SP $\left(477^{\circ} \mathrm{C}\right)$ and its associated thermal decomposition. As suggested by Churaman et al. ${ }^{17}$ this may include release of volatile $\mathrm{O}$ and $\mathrm{OH}$ radical species from decomposition of the perchlorate which may then interact with either of the two solid phase materials present, leading to a sustained reaction.

In a $\mathrm{N}_{2}$ atmosphere (Fig. 1e and 2e), energetic pSi/SP displayed a similar sudden change in the FTIR spectra with an onset of approximately $270{ }^{\circ} \mathrm{C}, 70{ }^{\circ} \mathrm{C}$ higher than in the presence of air. This correlated with an exothermic reaction observed by means of DSC commencing at around $270{ }^{\circ} \mathrm{C}$ with a sharp peak at $300^{\circ} \mathrm{C}$. DSC and FTIR results for blank pSi in $\mathrm{N}_{2}$ (Fig. $1 \mathrm{~b}$ and $2 \mathrm{~b}$ ) indicate that the surface hydride desorption commences at approximately $270{ }^{\circ} \mathrm{C}$, and this desorption appears to be an important first step leading to commencement of the energetic reaction, in the absence of oxygen. Becker et al. ${ }^{18}$ reached the same conclusion. Again, these reactions occur at a temperature lower than the melting point or decomposition point of the SP.

An additional observation recorded on the DSC scans of EM's run in air (Fig. 1d and 2d) is a shoulder in the main exothermic peak at $272{ }^{\circ} \mathrm{C}$, a feature not observed in the samples in $\mathrm{N}_{2}$ (Fig. 1e and 2e). This shoulder may be due to afterburning reactions of unreacted $\mathrm{pSi}$ with the atmospheric $\mathrm{O}_{2}$ within the DSC. Afterburning reactions are common in fuelrich samples which is a possibility with the smaller samples prepared in this study. As noted in the experimental section, loading of small samples of pSi was difficult due to precipitation of the SP on the exterior face of the wafer, leading to variability of the quantity and distribution of the SP within the pSi pores. Additionally, the porosity of the pSi in this investigation (65\%) was slightly lower than the calculated ideal porosity required to achieve a stoichiometrically balanced mixture $(70-72 \%),{ }^{2}$ indicating that the system investigated here was fuel rich, thereby facilitating afterburning reactions.

\section{Decomposition and reaction of $\mathbf{p S i} / \mathrm{PFPE}$ energetic materials}

Pure PFPE heated in air (Fig. If and 2f) displayed a strong and consistent peak at about $985 \mathrm{~cm}^{-1}$, attributed to C-F bond stretching vibrations. ${ }^{27}$ Strong broad absorption bands centred at $\approx 1200 \mathrm{~cm}^{-1}$, and a weak band centred at $\approx 744 \mathrm{~cm}^{-1}$ correspond to multiple $\mathrm{C}-\mathrm{C} / \mathrm{C}-\mathrm{O} / \mathrm{C}-\mathrm{F}$ vibrations. ${ }^{27}$ These bands persisted until approximately $400{ }^{\circ} \mathrm{C}$ when they disappeared and were replaced by a weaker broad absorption centred at 1050 $\mathrm{cm}^{-1}$. DSC scans of PFPE indicate a very weak change in the baseline commencing at $\approx 320{ }^{\circ} \mathrm{C}$ and complete by $400{ }^{\circ} \mathrm{C}$. In the DSC, it was noted that the aluminium pan was heavily tarnished after the acquisition of the scans of the PFPE samples were analysed (pans for other samples were not affected in this way), indicating that the sample was pyrolysing at these temperatures, releasing various reactive/oxidative species (instead of simply boiling away) as seen in other fully fluorinated polymers. ${ }^{33}$

The FTIR scans of pSi/PFPE EM heated in air (Fig. 1g, $2 \mathrm{~g}$ and 3e) were almost indistinguishable from the appearance of blank pSi in air except for the presence of the PFPE peak at $985 \mathrm{~cm}^{-1}$ and the band at $1200 \mathrm{~cm}^{-1}$. Oxidation of the pSi surface due to the oxygen in the air was evident at the same transition temperature of approximately $250{ }^{\circ} \mathrm{C}$ but appeared less intense compared to the spectra of blank pSi heated in air. In accordance with this observation, the DSC results of pSi/PFPE in air showed the same exothermic process as blank pSi in air but with a broader transition. No clear exotherms were observed to indicate an energetic reaction. One possible explanation for this is that the presence of the PFPE within the pores limits the rate of diffusion of oxygen into the surface such that the pSi reacts slowly with $\mathrm{O}_{2}$ prior to pyrolysis of the PFPE.

In contrast, $\mathrm{pSi} / \mathrm{PFPE} \mathrm{EM}$ in $\mathrm{N}_{2}$ displayed a different profile (Fig. 1h, 2h, and 3e). The typical pSi peaks $\left(910,2213 \mathrm{~cm}^{-1}\right)$ and PFPE peaks and bands $\left(985 \& 1200 \mathrm{~cm}^{-1}\right)$ were present and persisted until above $350{ }^{\circ} \mathrm{C}$. The strong exothermic transition observed in the DSC occurring at $397^{\circ} \mathrm{C}$ correlated with the loss of most of the PFPE peaks in the FTIR spectra from $390{ }^{\circ} \mathrm{C}$ onwards and also strongly attenuated pSi hydride peaks centred at 910 and $2213 \mathrm{~cm}^{-1}$. Simultaneously, a peak at $1029 \mathrm{~cm}^{-1}$ (very weak prior to the transition) increased, potentially indicating production of $\mathrm{SiF}_{4}$. Some remnants of the pSi surface were seen in the FTIR spectra above this temperature and may be due to the presence of unreacted pSi left after all of the PFPE has been consumed. The peak at $1029 \mathrm{~cm}^{-1}$ was the only indication of a reaction product $\left(\mathrm{SiF}_{4}\right)$. Alternative species (such as $\mathrm{HF}$ at $3750-4250 \mathrm{~cm}^{-1}$ ) were not observed.

When the $\mathrm{pSi} / \mathrm{PFPE}$ results are compared to the $\mathrm{pSi} / \mathrm{SP}$ heated in $\mathrm{N}_{2}$ it is apparent that the energetic reaction occurred at a far higher temperature $\left(\approx 400{ }^{\circ} \mathrm{C}\right.$ for PFPE compared to $300{ }^{\circ} \mathrm{C}$ for $\mathrm{SP})$. For $\mathrm{pSi} / \mathrm{SP}$, it was concluded that desorption of the surface hydride from the $\mathrm{pSi}$ was the initial step in the energetic reaction. For pSi/PFPE, it appears that the reaction did not occur even above the temperature required to commence hydride desorption, but was delayed until pyrolysis of the PFPE occurred at about $400{ }^{\circ} \mathrm{C}$. Release of oxidising species from the PFPE during pyrolysis appears to be necessary to induce the energetic reaction. 
This mechanism is very similar to the reaction of other perfluorocarbon-based energetic materials. ${ }^{33}$

\section{Summary and conclusions}

Energetic materials based on pSi have the potential to be deployed in advanced integrated initiation systems and microelectromechanical actuator systems, ${ }^{2}$ yet real world applications are currently limited due to the extreme sensitivity of the material and uncertainty over the manner in which they react. Knowledge of the reaction mechanism may pave the way towards materials with fit-for-purpose sensitivity and performance. In an effort to further investigate the mechanism of reaction between $\mathrm{pSi}$ and two selected oxidising agents, thermal and spectroscopic methods were combined for the first time to yield more comprehensive information than use of either technique in isolation.

It was found that breaking of the $\mathrm{Si}-\mathrm{Si}$ back bonds behind the hydride surface upon reaction with atmospheric oxygen was sufficient to permit the SP to attack the surface and commence the energetic reaction. However, in the absence of oxygen, desorption of the hydride species from the pSi surface was a necessary step to initiate reaction of the pSi with SP. Turning our attention to pSi loaded with PFPE, the pSi surface was oxidised in an air atmosphere before having the opportunity to react with PFPE. Yet in a $\mathrm{N}_{2}$ atmosphere, the reaction between pSi and PFPE was delayed until the onset of pyrolysis of the PFPE. Heating a sample slowly under these controlled conditions is a departure from the normal mode of the explosive reaction of these materials, but the information gained in this way provides important insights into the earliest stages of the reaction.

\section{Acknowledgements}

This work is supported by funding from the Centre of Expertise in Energetic Materials, a collaborative research partnership between Flinders University and the Defence Science and Technology Group. The authors gratefully acknowledge Prof. Paul Kirkbride and Dr Jon Campbell (Flinders University) for their assistance and support with the calorimetric and infrared testing, and Mr Richard Vincent (Warsash Scientific Pty Ltd) for provision of the Linkam FTIR600 equipment essential to this investigation. We also acknowledge the facilities, and the scientific and technical assistance of the Australian Microscopy and Microanalysis Research Facilities, South Australian Node.

\section{Notes and references}

1 H. Foll, M. Christopherson, J. Carstensen and G. Hasse, Mater. Sci. Eng., R, 2002, 39, 93-141.

2 M. du Plessis, Propellants, Explos., Pyrotech., 2014, 39, 348364, DOI: 10.1002/prep.201300053.

3 M. du Plessis, Mater. Sci. Eng., B, 2008, 147, 226-229, DOI: 10.1016/j.mseb.2007.08.010.

4 L. J. Currano and W. A. Churaman, J. Microelectromech. Syst., 2009, 18, 799-807.
5 S. Wang, R. Shen, Y. Ye and Y. Hu, Nanotechnology, 2012, 23, 435701, DOI: 10.1088/0957-4484/23/43/435701.

6 D. Clément, J. Diener, E. Gross, N. Künzner, V. Y. Timoshenko and D. Kovalev, Phys. Status Solidi A, 2005, 202, 1357-1364, DOI: 10.1002/pssa.200461102.

7 A. Plummer, V. Kuznetsov, J. Gascooke, J. Shapter and N. H. Voelcker, Propellants, Explos., Pyrotech., 2016, 41, 1029. 8 S. Wang, R. Shen, Y. Ye, Y. Hu, L. Wu and C. Yang, 2nd International Symposium on Laser Interaction with Matter, Proc. SPIE, 2013, 8796, 87960C.

9 W. A. Churaman, C. R. Becker, G. D. Metcalf, B. H. Hanrahan, L. J. Churano and C. R. Stoldt, Optical Technologies for Arming, Safing, Fuzing and Firing VI, Proc. SPIE, 2010, 7795, 779506.

10 A. Plummer, V. A. Kuznetsov, J. Gascooke, J. Shapter and N. H. Voelcker, J. Appl. Phys., 2014, 116, 054912, DOI: 10.1063/1.4892444.

11 N. W. Piekiel, W. Churaman, C. J. Morris and L. Currano, J. Microelectromech. Syst., 2013, 449-452.

12 B. A. Mason, S. F. Son, K. Y. Cho and B. W. Asay, Presented in part at the 45th AIAA/ASME/SAE/ASEE Joint Propulsion Conference, Denver, Colorado, 2009.

13 N. W. Piekiel, C. J. Morris, W. Churaman, M. E. Cunningham, D. M. Lunking and L. Currano, Propellants, Explos., Pyrotech., 2015, 40, 16-26, DOI: 10.1002/prep.2014000140.

14 M. Suceska, Test methods for explosives, Springer-Verlag, New York, 1995.

15 N. Kubota, Propellants and Explosives: Thermochemical aspects of Combustion, Wiley VCH, 2006.

16 D. Kovalev, V. Timoshenko, N. Künzner, E. Gross and F. Koch, Phys. Rev. Lett., 2001, 87, 086301.

17 W. Churaman, L. Currano, A. K. Singh, U. S. Rai, M. Dubey, P. Amirtharaj and P. C. Ray, Chem. Phys. Lett., 2008, 464, 198-201, DOI: 10.1016/j.cplett.2008.09.017.

18 C. R. Becker, L. J. Currano, W. A. Churaman and C. R. Stoldt, ACS Appl. Mater. Interfaces, 2010, 2, 2998-3003, DOI: 10.1021/ am100975u.

19 V. S. Parimi, S. A. Tadigadapa and R. A. Yetter, Chem. Phys. Lett., 2014, 609, 129-133, DOI: 10.1016/j.cplett.2014.06.049.

20 V. S. Parimi, S. A. Tadigadapa and R. A. Yetter, Combust. Sci. Technol., 2014, 187, 249-268, DOI: 10.1080/ 00102202.2014.973493.

21 D. B. Mawhinney, J. A. Glass and J. T. Yates, J. Phys. Chem. B, 1997, 101, 1202-1206, DOI: 10.1021/jp963322r.

22 J. Salonen, V. P. Lehto and E. Laine, Appl. Phys. Lett., 1997, 70, 637, DOI: 10.1063/1.118294.

23 A. Plummer, V. Kuznetsov, T. Joyner, J. Shapter and N. H. Voelcker, Small, 2011, 7, 3392-3398, DOI: 10.1002/ smll.201101087.

24 S. K. Lazarouk, A. V. Dolbik, P. V. Jaguiro, V. A. Labunov and V. E. Borisenko, Semiconductors, 2005, 39, 3.

25 Air, Instrument Grade, compressed, http://www.boc.com. au/shop/en/au-boc-industrial-store/air-instrument-gradecompressed, accessed 06/04/2016.

26 G. Ritzhaupt, J. Chem. Phys., 1975, 62, 1982, DOI: 10.1063/ 1.430688 . 
27 J. Pacansky, M. Miller, W. Hatton, B. Liu and A. Scheiner, J. Am. Chem. Soc., 1991, 113, 329-343.

28 G. Scardera, T. Puzzer, G. Conibeer and M. A. Green, J. Appl. Phys., 2008, 104, 104310, DOI: 10.1063/1.3021158.

29 Y.-H. Kim, M. S. Hwang, H. J. Kim, J. Y. Kim and Y. Lee, J. Appl. Phys., 2001, 90, 3367, DOI: 10.1063/1.1402152.
30 A. E. Guber and U. Kohler, J. Mol. Struct., 1995, 349, 209-212. 31 M. Hoshino, Y. Kimachi and A. Terada, J. Appl. Polym. Sci., 1996, 62, 207-215.

32 D. Devlin and P. J. Herley, React. Solids, 1987, 3, 75-84.

33 E.-C. Koch, Metal-fluorocarbon based energetic materials, Wiley-VCH, Weinheim, 2012. 